амплитуды забросов и просадок термических напряжений на переходных режимах на выпускных клапанах с теплоизолирующим покрытием. Используется нестационарная математическая модель на основе метода конечных элементов.

\title{
USE A THERMAL COATING FOR IMPROVED HEAT EXHAUST VALVES CONDITION FORCED DIESEL A.V. Trynov, S.A. Samiylenko
}

Are the results of the calculation research Heat-Stress exhaust valve status fast tractor diesel engine at steady-state and transient conditions reset-failed to load. The influence of the insulating enamel coating on the Heat-Stress status of the valve. Note the decline in the amplitude of casting and drawdowns on transient thermal stresses on the exhaust valves with thermal insulation coating. Non-stationary used a mathematical model based on the finite element method.

\section{Т.М. Колеснікова , В.Г. Заренбін}

\section{АНАЛІЗ ДВИГУНІВ 3 МОДУЛЬНИМ ВІДКЛЮЧЕННЯМ ЦИЛІНДРІВ}

\begin{abstract}
Розглядаються існуючі конструкиії автомобільних двигунів, щзо реалізують різні способи відключення ичиліндрів. Виявлено недоліки і переваги двигунів з різними способами відключення ичиліндрів. Відмічається, що модульні двигуни мають найбільшу паливну економічність, однак вони відрізняються складністю та ненадійністю конструкиії. Також наведено, щео у безшатунному двигуні з кривошипно-кулісним механізмом крім можливості підвищення ефективного ККД через малі механічні втрати, конструктивно простіше реалізується модульне відключення ичиліндрів.
\end{abstract}

\section{Вступ}

Пріоритетним напрямком розвитку автомобільних чотиритактних бензинових ДВЗ на сучасному етапі, як і раніше, $є$ поліпшення їх паливної економічності і зниження токсичності відпрацьованих газів (ВГ). На сьогодні такі ДВЗ у процесі доробки і тривалої експлуатації прийшли до свого логічного завершення, класична схема 3 кривошипно-шатунним механізмом (КШМ) вже не в змозі забезпечити подальше удосконалення двигуна i покращення його експлуатаційних властивостей, тобто резерви покращення показників сучасних ДВ3 практично вичерпано. Основною причиною погіршення економічних характеристик бензинових ДВЗ в часткових режимах є дроселювання суміші на впуску. Серед альтернативних способів регулювання навантаження можна виділити регулювання робочого об'єму двигуна шляхом зміни кількості працюючих циліндрів - так зване відключення циліндрів. В сучасному двигунобудуванні метод регулювання потужності відключенням циліндрів набуває широкого практичного застосування. Системи відключення групи циліндрів застосовують на двигунах багатьох провідних автомобілебудівних фірм. Найбільш перспективним вважається, так зване, модульне відключенні циліндрів на малих і середніх навантаженнях, на яких двигун працює основну частину часу. Однак існують проблеми реалізації модульного відключення циліндрів в існуючих ДВ3, а саме в модульних двигунах 3
КШМ колінчасті вали відповідних модулів з'єднуються розміщеною поміж ними муфтою, до якої пред'являються дуже високі вимоги. Робота муфти повинна бути строго синхронізована 3 роботою систем (живлення, запалювання, газорозподілу) модулів, що підключаються, також модульний двигун значно поступається класичному ДВЗ по габаритам і масі, має дуже складну і ненадійну конструкцію.

На сьогодні дослідження ДВЗ з модульним відключенням циліндрів (модульних двигунів) ведуться в США, Німеччині, Японії, Швеції, Росії та ін. країнах.

У статті приведено аналіз двигунів 3 відключенням циліндрів.

\section{Регулювання робочого об'єму двигуна}

Як вже зазначалося вище, ДВЗ, що застосовуються на автомобільному транспорті працюють у постійно змінюваних навантажувальних режимах. При цьому більшість часу займають режими малих навантажень та холостого ходу. При цьому, номінальна потужність двигуна використовується лише частково. Як відомо з теорії ДВЗ, ефективна потужність двигуна, крім ефективного середнього тиску, тактності, частоти обертання, залежить також і від робочого об'єму двигуна. Тобто, за інших рівних умов, доцільно було б мати для кожного навантажувального режиму двигун 3 певним робочим об'ємом. Іншими словами, при зниженні навантаження робочий об'єм повинен зменшуватись і на-

(C) Т.М. Колеснікова , В.Г. Заренбін, 2016 40 
впаки. Очевидно, що при такій постановці питання необхідність в дроселюванні суміші на впуску, тобто кількісного регулювання потужності в бензинових двигунах, відпадає. Тобто відпадає і вирішення питання погіршення показників ДВЗ на часткових режимах через зменшення кута відкриття дросельної заслінки. Існують два принципово різні шляхи вирішення даної проблеми: ступінчаста i плавна зміна робочого об'єму двигуна при змінюванні потрібного навантаження. Розглянемо більш докладно кожен з цих напрямків.

Плавне регулювання робочого об'сму

Робочий об'єм циліндра двигуна, як відомо, залежить від двох конструктивних параметрів: ходу поршня і діаметру циліндра. Очевидно, що регулювання робочого об'єму за рахунок зміни діаметру циліндра $є$ неможливим. Змінний хід поршня можливо реалізувати при застосуванні специфічних силових механізмів. Серед двигунів відомо лише один варіант реалізований свого часу в дослідному зразку - п'ятициліндровий двигун 3 діаметром циліндра 85,7 мм і ходом поршня, що змінювався від 26 до 108 мм [1]. У цьому двигуні (рис.1) при зміні ходу поршня від 102 до 51 мм механічні втрати знижуються на 40 \%, але при максимальному ході поршня вони більше на $14 \%$ за втрати в класичному ДВЗ з КШМ того ж самого об'єму. Однак, основним недоліком даної конструкції $\epsilon$ незрівноваженість двигуна.

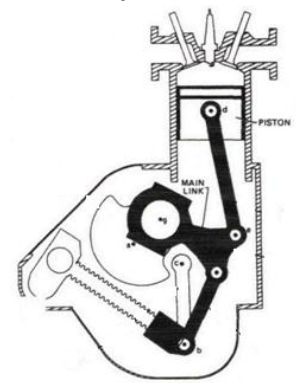

Puc. 1. Схема двигуна Poliot

Ідеї інших винахідників стосовно регулювання робочого об’єму двигуна за рахунок зміни ходу поршня знайшли відображення лише в патентних документах і практичної реалізації не отримали (наприклад, [2]).

Існує аксіальна схема силового механізму ДВ3. Регулювання робочого об'єму в таких двигунах відбувається за рахунок зміни кута нахилу шайби. Двигуни подібних конструктивних схем були реалізовані інженерами австралійської фірми Scalzo [3].

В ході досліджень цих двигунів було отримано економію палива на рівні 25-30\%.

Ступінчасте регулювання робочого об'єму
На сьогодні відома велика кількість схем двигунів з КШМ, в яких застосовано ступінчасте змінення робочого об'єму за рахунок регулювання кількості працюючих циліндрів. Зміну кількості працюючих циліндрів можливо здійснити за кількома напрямами. Найпростішим способом є припинення подачі палива у відключені циліндри [4]. Широкі дослідження у цьому напрямку в різні часи проводились в Національному транспортному університеті (м. Київ). [5]. Сутність цього методу полягає у встановленні на ділянці між карбюратором і впускним клапаном заслінки, яка при необхідності відключення циліндру перекриває переріз відповідного впускного трубопроводу. Так, при відключенні паливоподачі в три циліндри з шести економічність двигуна в режимі холостого ходу покращується на 20,3 \%. Модифікацією відключення паливоподачі $€$ і так званий метод відключення окремих робочих циклів. Цей метод був запропонований у 60-х роках минулого сторіччя проф. П.І. Андрусенко, а потім отримав розвиток у роботах проф. А.З. Філіпова. [6]. Принципова відмінність такого методу регулювання навантаження від простого відключення паливоподачі полягає у тому, що подача палива у окремі циліндри вимикається на один чи декілька циклів. При цьому для отримання потрібної потужності варується кількість відключених циклів і тривалість такого відключення. Це дає змогу повністю виключити з конструкції двигуна дросельну заслінку. Однак, незважаючи на простоту таких методів відключення в працюючих циліндрах залишаються насосні втрати в клапанних щілинах. Тому, більш прогресивним, хоча й більш складним, є спосіб деактивації за рахунок повної зупинки газорозподілу у відключених циліндрах. Досягається це шляхом утримання клапанів газорозподілу у закритому стані. Системи подібних типів знайшли поширення у двигунах, що випускаються серійно (рис. 2)

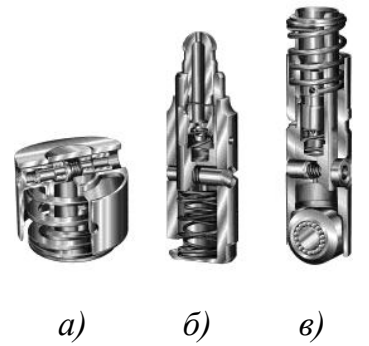

Рис. 2. Механізми зупинки клапанів газорозподілу: a - при верхньому розташуванні розподільчого валу і приводі клапанів штовхачем; б - при верхньому розташуванні розподільчого валу і приводі клапанів через важіль; в - при нижньому розташуванні розподільчого валу 
На сьогоднішній день відомо три принципових способи зупинки газообміну шляхом утримання клапанів у закритому стані за рахунок застосування:

- штовхачів і гідроопор клапанів спеціальної конструкції [7];

- складених коромисел клапанів, наявність зв'язку між частинами яких визначається потрібністю у роботі даного циліндру [8];

- кулачків розподільчого валу, який має можливість переміщуватись в осьовому напрямку, різної форми.

Автовиробники відмічають покращення паливної економічності за рахунок застосування вищевказаних систем приблизно на 8-12\%.

\section{Модульне відключення циліндрів}

Доцільність використання саме терміну «модульне» відключення циліндрів, обумовлюється тим, що автомобільний двигун у цьому випадку розділяється на декілька (відповідно до кількості циліндрів) незалежних частин (секцій, модулів), які вступають в роботу по мірі підвищення навантаження. Під незалежністю частин (модулів) мається на увазі можливість зупинки поршня у будь-якій 3 них при збереженні робочого процесу в інших. Повна відсутність у відключених циліндрах втрат на тертя у циліндро-поршневій групі, а також втрат на газообмін (за рахунок зупинки поршня) - визначають суттєву перевагу модульного способу відключення циліндрів у порівнянні з іншими способами деактивації.

Слід відмітити, що незважаючи на очевидні переваги модульного способу відключення циліндрів, на сьогодні не знайдено конструкції двигуна, придатної для серійного виробництва. Однак, існує ряд патентних рішень цієї конструкторської задачі. Одним $з$ перших можна вважати патент 1919 року [9], в якому шатун має телескопічну конструкцію, а жорсткий зв'язок між його частинами визначається положенням замка.

Складність і ненадійність самого механізму, а також системи керування, не дозволили цьому варіанту набути поширення.

Основну групу патентів по модульному відключенню циліндрів складають такі, в яких пропонується використовувати розрізний колінчастий вал, зв'язок між частинами якого забезпечується за допомогою спеціальних муфт. При цьому циліндри відключаються не по одинці, а групами.

Один з варіантів такої ідеї [10]. Зубчаста муфта виконана аналогічно з синхронізатору коробки передач (рис. 3). Синхронізація частин колінчастого вала за робочим процесом відбувається завдяки асиметричному розташуванню зубців зубчастої муфти, за швидкістю - за рахунок конічної тертьо- вої поверхні.

Крім застосування механічних зубчастих i фрикційних муфт $\epsilon$ також варіанти модульних конструкцій ДВЗ, в яких зв'язок між частинами колінчастого вала забезпечується електромагнітними муфтами.

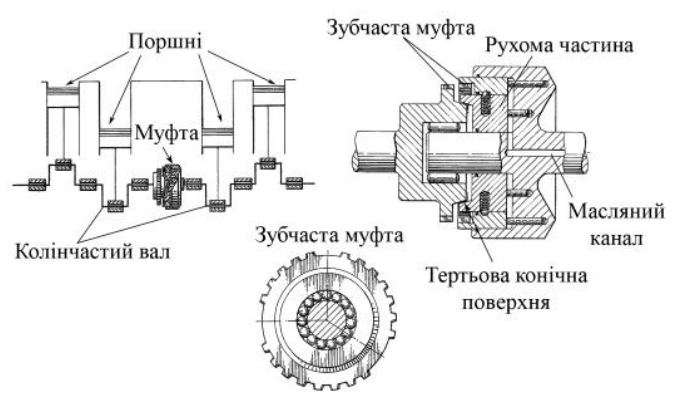

Рис. 3. Ідея розрізного колінчастого вала

Складності у створенні двигунів модульної конструкції з відключенням циліндрів шляхом зупинки поршнів відмічають і інші дослідники цієї технічної проблеми.

Таким чином, на сьогодні не знайдено прийнятної конструкції двигуна 3 модульним відключенням циліндрів. Однак, цінність проведених різними дослідниками експериментів на таких двигунах, доводить можливість досягнення суттєвого рівня економічності, за рахунок зупинки поршнів не менш, ніж $30 \%$.

Одним 3 можливих конструктивних варіантів двигуна, що дозволяє без суттєвих ускладнень застосувати модульну конструкцію, є безшатунний ДВЗ, у якому замість звичайного кривошипношатунного механізму застосовується кривошипнокулісний механізм [11].

Безшатунний двигун 3 модульним відключенням циліндрів

Відмінною рисою схеми двигунів із кривошипно-кулісним механізмом $є$ малі втрати на тертя у всьому діапазоні навантажень і частоти обертання, повна динамічна зрівноваженість і рівномірність ходу. Ці переваги пов'язані з тим, що в безшатунному двигуні шток здійснює виключно прямолінійний рух, у зв'язку з чим бічні навантаження на поршень відсутні.

У безшатунному двигуні робочий процес здійснюється як у звичайному чотиритактному бензиновому ДВЗ. Аналіз безшатунного двигуна з кривошипно-кулісним механізмом показує, що в цьому двигуні, крім можливості підвищення ефективного ККД через малі механічні втрати, конструктивно простіше реалізується модульне відключення циліндрів. 


\section{Заключення}

Проведений аналіз показав, що найбільш ефективним, з позиції покращення паливної економічності, є використання методу регулювання потужності за рахунок зміни робочого об'єму двигуна. Покращення паливної економічності при цьому сягає більше $30 \%$.

Відсутність на сьогоднішній день працездатних зразків автомобільних двигунів 3 регулюванням робочого об'єму обумовлена, насамперед, конфліктом між поліпшенням економічних показників і ускладненням конструкції та погіршенням масо-габаритних характеристик двигунів.

Перспективною конструкцією двигуна зі змінним робочим об'ємом, за рахунок відключення циліндрів шляхом зупинки поршня, є безшатунний ДВ3 із кривошипно-кулісним силовим механізмом.

\section{Список літератури:}

1. Poliot H.N. A variable-Displacement SI Engine / H.N. Poliot, W.R. Delameter, C.W. Robinson // SAE Congress 1977. - № 770114. - 19 pp. 2. Thorvald N., Olson Ormsby, Variable volume. 1972 . Piston stroke control mechanism, William F. O'Dea. Pat. 3,633,429. 3. Joseph Scalzo, 1988. Wobble plate engine stabilizer mechanism. Patents Pty. Ltd. U.S. Pat 4,727,761. 4. Yasuo Nakajima, Internal combustion engine system with an air-fuel mixture shut off means. 1978. Pat. 4,106,471. 5. Разработка и исследование экспериментальной системы питания двигателя 3М3-53 с отключаемыми иилиндрами. /Научный руководитель Гутаревич Ю.Ф. // Научный отчет НИР - 1984, КАДИ. № гос. регистрачии 01.83.0077270. 6. Филиппов А.3. Повышение экономических и экологических показателей ДВС отключением отдельных рабочих иииклов: Дис... д-ра техн. наук: 05.04.02. - K., 1996. - 460 c. 7. loan Manole, Burak A. Gecim, William C Albertson, Stop valves. 2006. Valve deactivator latching assembly. US. Pat. 7,111,597 B2. 8. Yoshihiro Fujiyoshi,Stop klapanov_razreznye rocker.1997. Variable cylinder-operation controlled internal combustion engine. Pat. 5,636,609. 9. M. Marius-Jean-Baptiste-Julien, MOTBURS DIVBRS.1919. Stoppage of piston. FR. Pat.
494.662.10. Alan Cohan, SYNCHRONIZING AND INDEXING CLUTCH. 1978. Stoppage of piston .Clutch crankshaft. Pat. 4,069,803. 11. Мищенко Н.И. Нетрадичионные малоразмерные двигатели внутреннего сгорания. В 2-х томах. Т. 1.: Теория, разработка и испытание нетрадиционных двигателей внутреннего сгорания. - Донеик: «Лебедь», $1998-228$ c.

\section{Bibliography (transliterated):}

1. Poliot, H.N., Delameter, W.R., Robinson, C.W. (1977) A variable-Displacement SI Engine. SAE Congress, № 770114, 19 pp. 2. Thorvald, N., Olson Ormsby, Variable volume. 1972 . Piston stroke control mechanism, William F. O'Dea. Pat. 3,633,429. 3. Joseph Scalzo, 1988. Wobble plate engine stabilizer mechanism. Patents Pty. Ltd. U.S. Pat 4,727,761.

4. Yasuo Nakajima, Internal combustion engine system with an air-fuel mixture shut off means. 1978. Pat. 4,106,471. 5. Gutarevich U.F. (1984) «Development and searching of experimental system of suppying engine ZMZ-53 with switched off cylinders», [ Razrabotka I issledovanie eksperimental'noj sistemi pitanija dvigatelja ZMZ-53 s otkluchaemimi cilindrami^ Nauchnij otchet NIR], Scientific report NIR, KADI. № gos. registration 01.83.0077270. 6. Fillipov A.Z. 1996, Increasing economical and ecological paramaters of ICE with switched off divided workable cycles: Dis... doctor of technical sciences:[Povishenie ekonomicheskih I ekologichezkih pokazatelej DVS otklucheniem otdelnih rabochih ciklov: Dissertacija doktora tehnicheskih nauk] 05.04.02. - Kiev, 460 p. 7. loan Manole, Burak A. Gecim, William C Albertson, Stop valves. 2006. Valve deactivator latching assembly. US. Pat. 7,111,597 B2. 8. Yoshihiro Fujiyoshi,Stop klapanov_razreznye rocker.1997. Variable cylinder-operation controlled internal combustion engine. Pat. 5,636,609. 9. M. Marius-Jean-Baptiste-Julien, MOTBURS DIVBRS.1919. Stoppage of piston. FR. Pat. 494.662. 10. Alan Cohan, SYNCHRONIZING AND INDEXING CLUTCH. 1978. Stoppage of piston .Clutch crankshaft. Pat. 4,069,803. 11. Mischenko N.I. (1998), Untraditional small-size engines of internal combustion. 2 volumes. $V .1$. Theory, development and testing untraditional engines of internal combustion [Netradicionnie malorazmernie dvigateli vnutrennego sgoranija. V 2-h tomah. T. 1.: Teorija, razrabotka I ispitanie netradicionnih dvigatelej vnutrennego sgoranija], Donezk, «Lebed», 228 p.

Надійшла до редакиї 09.06.2016 p.

Колеснікова Тетяна Миколаївна - канд. техн. наук, доцент кафедри експлуатації та ремонту машин Придніпровської державної академії будівництва та архітектури, Дніпропетровськ, Україна, e-mail: tnk2704@ mail.ru.

Заренбін Володимир Георгійович - доктор техн. наук, професор, завідувач кафедри експлуатації та ремонту машин Придніпровської державної академії будівництва та архітектури, Дніпропетровськ, Україна, е-таil: zvg@mail.pgasa.dp.ua

\section{АНАЛИЗ ДВИГАТЕЛЕЙ С МОДУЛЬНЫМ ОТКЛЮЧЕНИЕМ ЦИЛИНДРОВ}

\section{Т.Н. Колесникова, В.Г. Заренбин}

Рассмотрены существующие конструкции автомобильных двигателей, в которых реализуются различные способы отключения цилиндров. Выявлены недостатки и преимущества двигателей с различными способами отключения цилиндров. Отмечено, что модульные двигатели имеют наибольшую топливную экономичность, однако они отличаются сложностью и ненадежностью конструкции. Также приведено, что в бесшатунном двигателе с кривошипно-кулисным механизмом кроме возможности повышения эффективного КПД, из-за малых механических потерь, конструктивно проще реализуется модульное отключение цилиндров. 


\title{
ANALYSIS OF ENGINES WITH MODULE DISCONNECTING OF CYLINDERS
}

\section{T.N. Kolesnikova, V. G. Zarenbin}

Regarded the constructions of automobile engines existed, in which the different processes of cylinder's disconnection take place. Found the disadvantages and pluses of engines with different methods of cylinder's disconnection. Marked that module engines have the highest fuel economy, but they are different with their ability to be more complex and unreliable construction. Also shown that in the crank-rocker engine without piston-rod has not only a possibility of increasing of effective Energy conversion efficiency because of low mechanical losses, where the module cylinder's disconnection is implemented more easily.

\section{В.И. Кубич, А.В. Юдиценко, Н.В. Блощинская ФЕНОМЕНОЛОГИЧЕСКИЙ ПОДХОД К ОЦЕНКЕ ТРИБОЛОГИЧЕСКОГО
СОСТОЯНИЯ СОПРЯЖЕНИЙ ЦПГ ДВС}

\begin{abstract}
Рассмотрены подходы к оченке обозначенных параметров трибологического состояния контакта поверхностей в сопряжениях «поршневое кольцо - гильза цилиндра», «поршень - гильза цилиндра» в начальный момент движения и мальх перемещениях с использованием эксплуатачионных натурных элементов конструкции на оборудовании машины СМЦ-2. При этом микропроцессы, происходящие на границе приповерхностных слоев материалов трибологических систем, рассматриваются как феномен. Представлены расширенные возможности разработанного программного продукта по моделированию тепломеханического нагружения контакта «гильза цилиндра - пориневое кольцо», позволяющие выполнять оченку диаметрального износа гильзы цилиндра на прогнозной наработке ДВС.
\end{abstract}

\section{Введение}

Решение научно-технических задач по обеспечению высокого уровня надежности трибосопряжений кривошипно-шатунного механизма ДВС при оптимизации тепломеханического нагружения, применение новых конструкционных материалов в условиях формирования поверхностных износостойких структур предполагают дальнейшую разработку и усовершенствование существующих методов определения износа рабочих поверхностей. Контактное взаимодействие поверхностей элементов сопряжений цилиндро-поршневой группы (ЦПГ) через формирующиеся смазочные слои при протекании рабочих процессов вследствие реализации термодинамического цикла в цилиндре двигателя предопределяет их трибологическое состояние. При этом неминуемо будут протекать сложные микропроцессы формирования и разрушения адгезионно-когезионных связей, адсорбционного взаимодействия между компонентами:

- на границах приповерхностных слоев материалов трибологических систем, например, «СЧ2444 - Lukoil-Super 15W40 - 4Х5МФ1С-Ш» для сопряжения «гильза-цилиндра - компрессионное кольцо», «СЧ24-44 - Lukoil-Super 15W40 - АК4-1» для сопряжения «гильза цилиндра - юбка поршня»;

- между многоатомными молекулами смазочного материала в присутствии поверхностноактивных веществ, метильными и метиленовими группами;

- например, между карбоксильными группами изомеров и активными центрами металлов.
Реальные эксплуатационные микропроцессы, которые происходят на границе приповерхностных слоев между компонентами каждой из трибологических систем, можно рассматривать, как некоторую «идеальную сущность - феномен, которая имеет непосредственную достоверность, и познать ее можно только интуитивно» [1]. Причем, познать их степень значимости для оценки трибологического состояния возможно не только выполняя моделирование характера и условий взаимодействия поверхностей на малогабаритных образцах, но и воспроизводя сам факт их проявления на эксплуатационных натурных образцах. Последнее представляется сложным, однако полученный результат будет более объективным и значимым для прогнозной оценки износа на любом из этапов изнашивания поверхностей трения. Исходя из приведенного, такой подход в оценке трибологического состояния сопряжений ЦПГ представляется как феноменологический, поскольку оценивается не сама «идеальная сущность», а факт ее проявления и влияния на оцениваемый параметр по форме, наиболее приближенной к эксплуатационной.

\section{Анализ ранее изданных публикаций}

Режимы смазки и трения, при которых протекают процессы взаимодействия элементов трибосопряжений цилиндро-поршневой группы (ЦПГ) двигателей внутреннего сгорания (ДВС), являются предметом научных дискуссий и исследований. В настоящее время обозначились три основных направления для оценки трибологического состояния рассматриваемых 